\title{
High species richness in the shallow marine waters of south-east Australia
}

\author{
Noel Coleman ${ }^{1, *}$, Anne S. H. Gason ${ }^{1}$, Gary C. B. Poore ${ }^{2}$ \\ 'Marine and Freshwater Resources Institute, PO Box 114, Queenscliff, Victoria 3225, Australia \\ ${ }^{2}$ Museum of Victoria, 71 Victoria Crescent, Abbotsford, Victoria 3067, Australia
}

\begin{abstract}
The benthic infauna in 3 areas along $50 \mathrm{~km}$ of the coast of Victoria, south-east Australia. was investigated. Grab samples $\left(0.1 \mathrm{~m}^{2}\right)$ were collected from a depth range of 11 to $51 \mathrm{~m}$ at 12 to 14 sites within each area. Sediments at the sample sites were medium to coarse sand. The distribution of the fauna was related to depth and sediment type. Numbers of individuals and species increased as depth increased and as sediments became more poorly sorted. Species diversity, $H^{\prime}$, increased as sediments became more poorly sorted. Species diversity and evenness, $J^{\prime}$, were greatest at intermediate values for mean grain size. The fauna was extremely species rich. The 104 samples $(=$ a total sample area of $10.4 \mathrm{~m}^{2}$ ) yielded 60258 individuals and 803 species. Few species were highly abundant and $51 \%$ of species collected are apparently undescribed. The data show that species richness may be as high in shallow water as in the deep sea.
\end{abstract}

KEY WORDS: Benthos · Species richness $\cdot$ South-east Australia

\section{INTRODUCTION}

The diversity of deep-sea benthic communities has long been appreciated. Hessler \& Sanders (1967) noted that the paucity of animals in early deep-sea samples had given the false impression that diversity was low. Sanders (1968) analysed larger samples using rarefaction methods to estimate total species numbers. He found that 'the deep-sea benthic fauna appears to possess a relatively high diversity of the same general order as that present in the tropical shallow seas' and greater than that of temperate shelves. More recently, Grassle \& Maciolek (1992) also concluded, on the basis of quantitative samples from depths of 1500 to $2500 \mathrm{~m}$, that species richness was higher on the continental slope than on the adjacent shelf of the north-west Atlantic Ocean. They generalised this finding to suggest that, outside of the tropics, shallow-water marine communities have relatively few species when compared with deep-sea communities. The assertion that, in temperate areas, species richness is particularly high in deep-sea communities has, however, been

•E-mail: n.coleman@msl.oz.au questioned. Poore \& Wilson (1993) showed that Grassle \& Maciolek's deep-sea data were atypically low on a global scale and suggested that shelf faunas of southeast Australia are also rich in species. Further, Gray (1994) found that the same number of species as found by Grassle \& Maciolek in the deep sea can be captured with fewer individuals on the Norwegian shelf.

During the late 1980 s a number of companies expressed interest in establishing a pulp and paper mill in East Gippsland, Victoria, south-east Australia. Effluent from the mill would be discharged into Bass Strait. Federal government guidelines require baseline and postimpact monitoring studies to be undertaken at the discharge and at 2 control sites in areas that are to receive pulp mill effluents. Previous, but very limited, sampling in the area had suggested that the fauna was extremely diverse (Parry et al. 1990). The present study was undertaken to provide preliminary quantitative data on distribution, abundance and seasonal variation in the benthos that could be used to plan subsequent work. The study provided these data (Coleman 1996) but also showed the area to be one of extreme species richness, and so is relevant to recent discussions on marine species richness (Grassle \& Maciolek 1992, Gray 1994). 


\section{METHODS}

Survey area and design. East Gippsland (area $27861 \mathrm{~km}^{2}$, population 67000 ) is a sparsely populated rural area fringing Bass Strait in Victoria, south-east Australia (Fig. 1). The major industries are timber (logging and saw-milling), agriculture, fishing and tourism. At present there are no sewage or effluent discharges from any part of the coast in this region.

The two most likely areas for effluent discharge from a mill to Bass Strait are off Waygara (Site W), west of the mouth of the Snowy River, and between Point Ricardo and Cape Conran (Site C). Both areas were sampled. A third area, east of Lake Tyers (Site T), was also sampled, thus making provision for a second control site should one of the other two become the impact site (Fig. 1).

Each area was defined by a $10 \mathrm{~km}$ square. Each square was stratified (Strata A-D), by distance from the shore, into 3 inner zones ( $2 \mathrm{~km}$ wide) and an outer zone ( $4 \mathrm{~km}$ wide) and 5 stations were randomly allocated to each stratum ( 20 stations per site). The stations covered a distance of $50 \mathrm{~km}$ along the coast and all were on medium to coarse sediments at depths between 11 and $51 \mathrm{~m}$.

In September 1990 each station was sampled to provide data on the distribution of benthos throughout the sample areas. At Stns T3 and C18, 3 replicates were taken; 9 replicates were taken at Stn W10 (to provide data on variability within stations), and 1 sample was taken at each of the remaining stations. Only 3 or 4 stations per stratum were subsequently processed (because of time constraints), and only these stations are shown in Fig. 1.

To provide data on seasonal variation, 3 replicate samples were taken in February and June 1991 from
Stns T3, T9, T18, W5, W10, W20, C2, C6 and C18. A fourth cruise, planned to provide samples over a whole year, was cancelled because the build-up of a sand bar closed the port from which sampling cruises were conducted.

Sampling methods. On the first cruise stations' positions were located using radar and on subsequent cruises by Global Positioning System. Samples were collected with a Smith-McIntyre grab, which sampled an area of $0.1 \mathrm{~m}^{2}$, and were preserved in $10 \%$ neutral formalin. At the Museum of Victoria, samples were sieved through a $0.5 \mathrm{~mm}$ mesh, and the animals retained were counted and identified to the lowest possible taxonomic level. Species identifications were made for Crustacea, Polychaeta, Mollusca, Pycnogonida and Echinodermata (except Ophiuroidea). Epifaunal groups such as sponges, hydroids, bryozoa and ascidians were not identified.

During the September cruise a sediment sample of 150 to $300 \mathrm{~g}$ was taken from each grab for grain size analysis using settling tube analysis (George \& Black 1991). The sediment was washed through a $63 \mu \mathrm{m}$ mesh to remove mud. The remaining sediment was oven dried for approximately $24 \mathrm{~h}$ at $100^{\circ} \mathrm{C}$. Any coarse material (of pebbles and shell fragments) was separated from the sand fraction by passing the sediment through a $4.76 \mathrm{~mm}$ mesh sieve. Sand and coarse fractions were analysed individually. Pebbles $>1 \mathrm{~cm}$ and shells and shell fragments $>3 \mathrm{~cm}$, which were too heavy to be released into the settling tube, were removed from the coarse fraction. Few samples contained mud. For the 6 samples which appeared muddiest, the total sample was dried and the mud content was calculated as a percentage of the total dry weight.

Analysis of results. Numbers of individuals $(n)$ and species $(s)$ were determined for each sample. For sta-

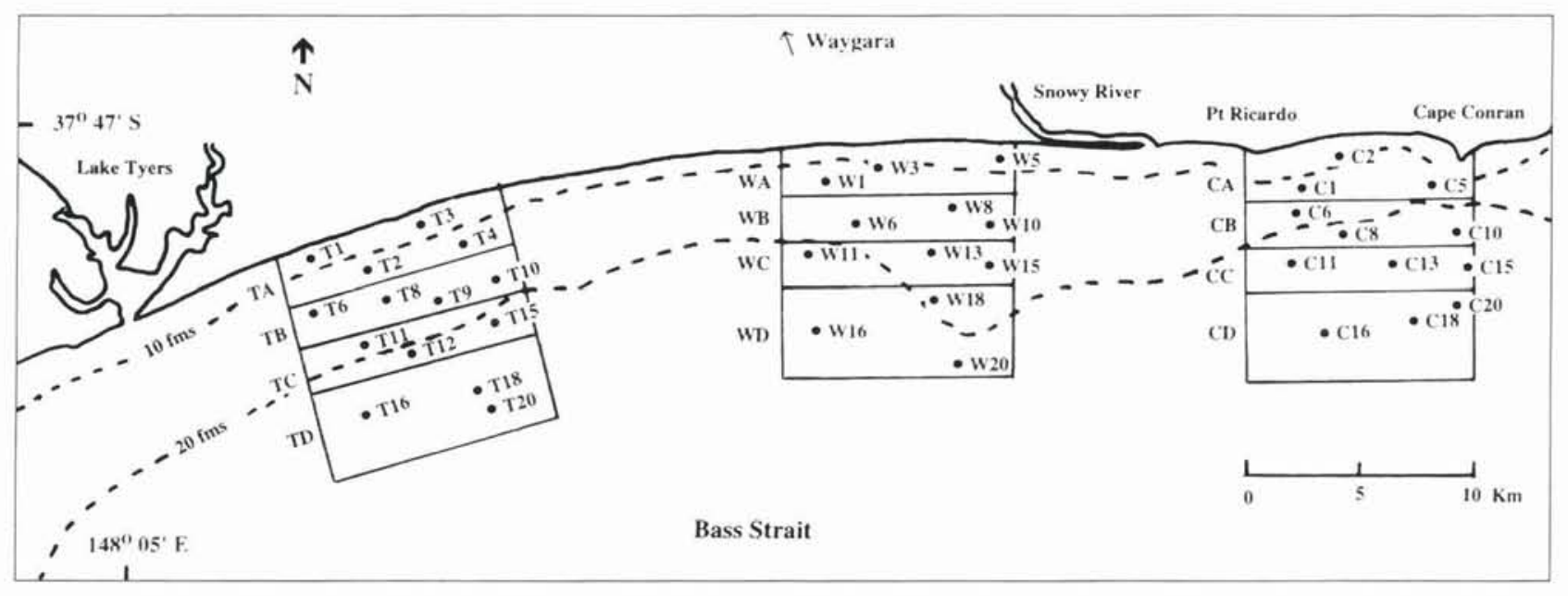

Fig. 1. Sampling sites ( $T, W, C)$ showing sampling stations (1-20 for each site) and strata (A-D for each site) 
tions with replicates, numbers of individuals and species summed over the replicates (per cruise) were also determined. The Shannon-Wiener diversity index, $H^{\prime}$ $\left(H^{\prime}=-\Sigma \mathrm{p}_{i} \ln \mathrm{p}_{i}\right.$ where $\mathrm{p}_{i}$ is the proportion of individuals in the $i$ th species), was calculated for each station. Evenness, $J$, was calculated using Pielou's formula $\left(J^{\prime}=H^{\prime} / \ln s\right)$.

Relationships between fauna, depth and sediment characteristics were investigated by regression analysis using data from the September cruise. Where faunal characteristics were related to 2 environmental variables, partial correlation was used to evaluate the relative importance of each. Numbers of individuals per station were $\log _{10}$ transformed for these analyses.

Fauna-sediment correlations were carried out on the sand and coarse fractions separately.

To show the rate at which new species were collected as more stations were sampled, species-area curves (i.e. plots of total species collected against total number of stations/samples sorted) were produced. Data from the September samples were used. Plots were produced for stations within areas and for all stations sampled. Only the first grab was used where replicates were taken. For a given number of samples the shape of the species-area curve may vary slightly, depending on the order in which the samples are added, although the total number of species collected will not change. To take this variation into account in generating the species-area curves, up to 100 random subsamples of $1,2,3 \ldots \mathrm{n}$ grabs were taken. The total number of species was determined for each subsample and then the mean and standard deviation for total number of species was calculated for each set of subsamples. Species-area curves were similarly generated for multiple samples taken at Stn W10 in September and for multiple samples taken (at W10) over the 3 sampling cruises.

Two plots of cumulative number of species against cumulative number of individuals were produced. For direct comparison with plots appearing in Grassle \& Maciolek (1992) and Gray (1994), a plot of total species against total individuals was produced. Stations sampled in September (including replicates) were combined in sequence from west to east starting with the lowest numbered station at the Tyers site and finishing with the highest numbered station at the Cape Conran site. Stations sampled in February and June were then added in the same sequence. To determine variations in the number of species for a given number of individuals, 100 random subsamples of $1000,2000 \ldots 23000$ individuals were taken from the September samples and the total number of species determined for each subsample. The mean and standard deviation for total number of species were calculated for each set of subsamples.

\section{RESULTS}

\section{General}

A total of 104 samples, equivalent to an area of $10.4 \mathrm{~m}^{2}$, were sorted. These yielded 60258 individuals and 803 species. All specimens have been retained and species lists are available from the authors. Of the species collected, $51 \%$ (409) are apparently undescribed. The number of individuals per grab $\left(0.1 \mathrm{~m}^{2}\right)$ ranged from 33 to 2824 (mean \pm SD, $580 \pm 394$ ) and the number of species from 17 to 198 (mean $\pm \mathrm{SD}, 97 \pm 40$ ). Species diversity, $H^{\prime}$, ranged from 1.8 to 4.6 , (mean $\pm \mathrm{SD}, 3.6 \pm$ 0.5 ) and evenness, $J^{\prime}$, from 0.4 to 0.9 (mean \pm SD, $0.81 \pm$ 0.08 ). Polychaetes, molluscs and crustaceans together provided $99 \%$ of the individuals and $98 \%$ of the species collected. When all the individuals collected are considered, no species showed a high degree of numerical dominance. Nineteen species each contributed $1 \%$ or more of the total. The most abundant of these was the polychaete Prionospio nirripa $15.5 \%$ of individuals collected). Within individual stations the degree of dominance by the most abundant species was up to $70 \%$, but was generally less than $20 \%$.

\section{Stations sampled in September}

Analysis by stratum

The 38 stations sampled in September gave 18509 individuals and 619 species (Table 1; for stations with replicates, values are for the first grab only so that all stations are compared on the same basis). Evenness at all stations was high, reflecting the fact that the samples were not dominated by a few highly abundant species. Of all the individuals collected, 21 species ( $3.4 \%$ of the total) each contributed $>1 \%$, and of the individuals collected in any one area, 39 species $(6.3 \%)$ each contributed $>1 \%$ (though generally $<5 \%$ ). The most abundant species was the polychaete Prionospio nirripa which provided $10 \%$ of all the individuals collected and $20 \%$ of the individuals at the Tyers stations. Within individual stations, dominance ranged from $5.4 \%$ (for Exogoninaesp. 517 at station W10) to $70 \%$ (for Prionospio nirripa at station T18) but was generally less than $20 \%$.

The mean number of individuals per station within strata ranged from 275 to 846 and the number of species ranged from 56 to 147 (Table 2). Polychaetes provided the highest mean number of individuals in 9 of the 12 strata and crustaceans provided the highest mean number of species in all strata.

Sixty-six species $(10.6 \%)$ were of relatively frequent occurrence in that they were found at $50 \%$ or more of all the stations. Eighty species $(12.9 \%)$ occurred at 
Table 1. Number of individuals $(n)$, number of species $(s)$, and species diversity $\left(H^{\prime}\right)$ and evenness $\left(J^{\prime}\right)$ at stations sampled in September. Each station is represented by 1 grab sample $\left(0.1 \mathrm{~m}^{2}\right)$. Only the first grab is included for those stations with replicates (T3, W10, C18)

\begin{tabular}{|c|c|c|c|c|c|c|}
\hline Stratum & Stn & Depth $(\mathrm{m})$ & $n$ & $s$ & $H^{\prime}$ & $J$ \\
\hline \multirow[t]{4}{*}{ TA } & $\mathrm{T} 1$ & 17 & 48 & 23 & 2.79 & 0.89 \\
\hline & $\mathrm{T} 2$ & 30 & 679 & 83 & 3.37 & 0.76 \\
\hline & $\mathrm{T} 3$ & 11 & 260 & 46 & 3.15 & 0.89 \\
\hline & $\mathrm{T} 4$ & 25 & 335 & 70 & 3.50 & 0.83 \\
\hline \multirow[t]{4}{*}{$\mathrm{TB}$} & T6 & 28 & 239 & 44 & 2.84 & 0.75 \\
\hline & T8 & 32 & 493 & 84 & 3.68 & 0.83 \\
\hline & T9 & 37 & 477 & 94 & 3.52 & 0.77 \\
\hline & T10 & 36 & 343 & 77 & 3.60 & 0.83 \\
\hline \multirow[t]{3}{*}{ TC } & $\mathrm{T} 11$ & 38 & 490 & 96 & 3.81 & 0.83 \\
\hline & T12 & 40 & 470 & 106 & 3.96 & 0.85 \\
\hline & $\mathrm{T} 15$ & 40 & 578 & 106 & 3.34 & 0.72 \\
\hline \multirow[t]{3}{*}{ TD } & T16 & 42 & 815 & 94 & 3.57 & 0.79 \\
\hline & T18 & 43 & 1151 & 87 & 1.76 & 0.39 \\
\hline & T20 & 44 & 499 & 66 & 1.81 & 0.43 \\
\hline \multirow[t]{3}{*}{ WA } & W1 & 27 & 401 & 87 & 3.77 & 0.84 \\
\hline & W3 & 24 & 347 & 72 & 3.46 & 0.81 \\
\hline & W5 & 17 & 211 & 45 & 2.69 & 0.71 \\
\hline \multirow[t]{3}{*}{ WB } & W6 & 31 & 511 & 113 & 4.05 & 0.86 \\
\hline & W8 & 27 & 404 & 103 & 4.02 & 0.87 \\
\hline & W10 & 29 & 315 & 86 & 4.06 & 0.91 \\
\hline \multirow[t]{3}{*}{ WC } & W11 & 36 & 390 & 125 & 4.22 & 0.87 \\
\hline & W13 & 32 & 556 & 98 & 3.91 & 0.85 \\
\hline & W15 & 32 & 1267 & 109 & 3.44 & 0.73 \\
\hline \multirow[t]{3}{*}{ WD } & W16 & 46 & 617 & 107 & 3.34 & 0.71 \\
\hline & W18 & 34 & 284 & 73 & 3.33 & 0.78 \\
\hline & W20 & 45 & 694 & 156 & 4.30 & 0.85 \\
\hline \multirow[t]{3}{*}{$\mathrm{CA}$} & $\mathrm{C} 1$ & 23 & 219 & 55 & 3.28 & 0.82 \\
\hline & $\mathrm{C} 2$ & 23 & 324 & 39 & 2.56 & 0.70 \\
\hline & C5 & 33 & 321 & 83 & 3.82 & 0.86 \\
\hline \multirow[t]{3}{*}{$\mathrm{CB}$} & C6 & 26 & 182 & 60 & 3.63 & 0.89 \\
\hline & C8 & 43 & 301 & 82 & 3.40 & 0.78 \\
\hline & C10 & 49 & 925 & 187 & 4.48 & 0.86 \\
\hline \multirow[t]{3}{*}{$\mathrm{CC}$} & C11 & 51 & 1446 & 168 & 3.37 & 0.66 \\
\hline & C13 & 50 & 537 & 129 & 4.21 & 0.87 \\
\hline & C15 & 50 & 554 & 143 & 4.17 & 0.84 \\
\hline \multirow[t]{3}{*}{$\mathrm{CD}$} & C16 & 48 & 239 & 85 & 3.79 & 0.85 \\
\hline & C18 & 50 & 212 & 73 & 3.86 & 0.90 \\
\hline & $\mathrm{C} 20$ & 50 & 375 & 98 & 3.75 & 0.82 \\
\hline
\end{tabular}

$50 \%$ or more of the stations in at least one area. Many of the most abundant species were also amongst the most frequently occurring, but many frequently occurring species were not amongst the most abundant. One hundred and sixteen species $(18.7 \%)$ were represented by only 1 individual, and 163 species $(26.3 \%)$ occurred at only 1 station.

Relationships between fauna depth and sediment

Sediments at the sample sites were predominantly medium to coarse sands. Mean grain sizes ranged from
0.30 to $0.93 \mathrm{~mm}$ and from 0.72 to $2.1 \mathrm{~mm}$ for the sand and coarse fractions respectively. Mud content, only determined for 6 stations, ranged from 0.7 to $4.7 \%$.

$n, s, H^{\prime}$ and $J^{\prime}$ correlated significantly with depth and with characteristics of the sand fraction (Figs. 2 to 4 ). $\log _{10} n$ and $s$ increased with depth and in more poorly sorted sediments, and $H^{\prime}$ increased in more poorly sorted sediments (described by linear regression). $H^{\prime}$ and $J^{\prime}$ peaked at intermediate values for grain size. The use of a second degree polynomial rather than a linear regression to relate $H^{\prime}$ and $J^{\prime}$ to mean grain size produced a substatial increase in $\mathrm{r}^{2}$ values (from 0.25 to 0.36 for $H^{\prime}$ and from 0.20 to 0.34 for $J^{\prime}$ ).

Depth and sediment characteristics are themselves interrelated and the effect of these interrelationships on correlations with the fauna was evaluated. Partial correlations (Table 3 ) showed the major factors associated with the fauna to be depth, sediment sorting (a measure of the spread of grain sizes around the median) and mean grain size. Correlations between the fauna and (sediment) skewness and kurtosis became non-significant when the effects of depth or sorting were removed by partial correlation, but
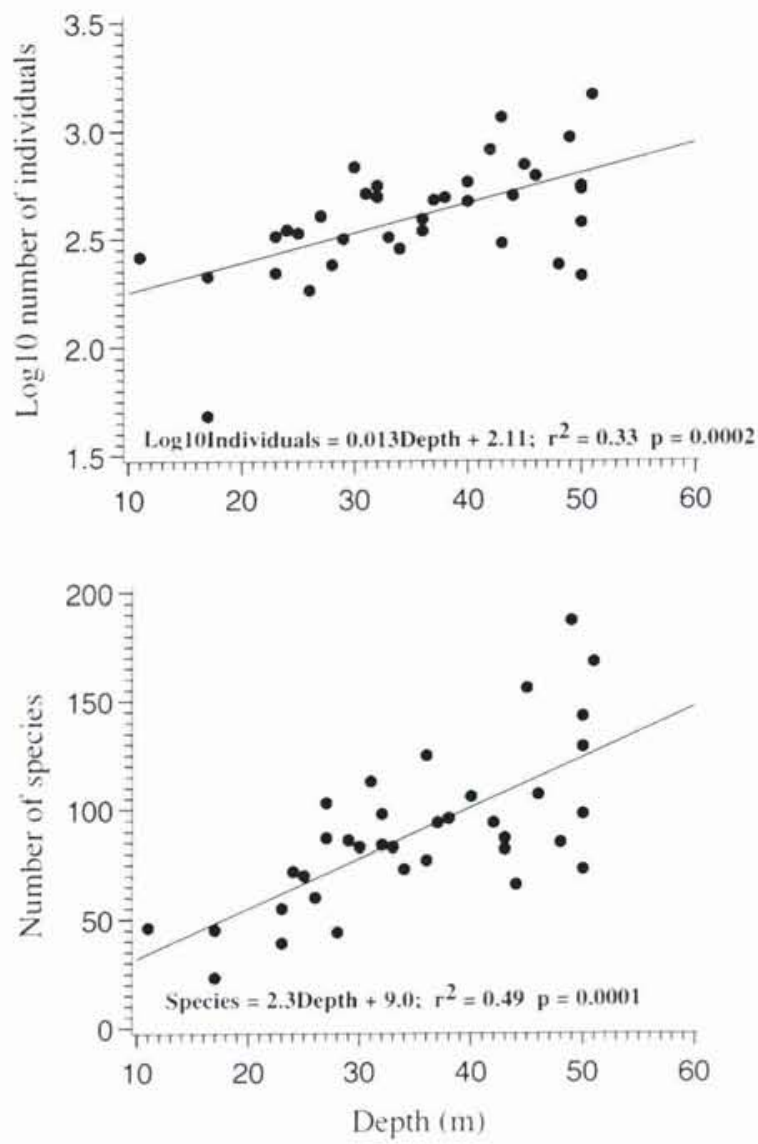

Fig. 2. Relationships between number of individuals and depth, and number of species and depth 
removing the effects of skewness and kurtosis had little effect on correlations with depth and sorting.

The number of individuals per station (Table 3 , Figs. 2 \& 3) was correlated with depth and sorting. Removing the effects of depth or sorting rendered correlation with the remaining variable non-significant. The number of species per station was correlated with depth and sorting. The correlation with depth became non-significant when the effects of sorting were removed, but that with sorting remained significant when the effects of depth were removed. Species diversity was correlated with mean grain size and sorting, and the correlation with each remained significant when the effects of the other was removed. Evenness was related only to mean grain size.

\section{Stations with replicates}

A total of 9 stations were sampled with 3 replicates per station. Of these 9 stations, 3 were sampled during all 3 cruises and 6 were sampled only in February and June (Table 4). These 63 samples provided 40377 individuals and 708 species. There were no highly abundant species; only 19 species each provided $1 \%$ or

Table 2. Mean values $( \pm$ SD) for numbers of individuals and species of the major taxa at the stations sampled in September. Stations are grouped by stratum. Only the first grab has been included for those stations with replicates

\begin{tabular}{|lllllc|}
\hline Stratum & Polychaetes & Molluscs & Crustaceans & Other taxa & Total \\
\hline Individuals & & & & & \\
TA & $202 \pm 186$ & $29 \pm 28$ & $89 \pm 44$ & $11 \pm 12$ & $331 \pm 262$ \\
TB & $234 \pm 61$ & $23 \pm 13$ & $127 \pm 79$ & $5 \pm 8$ & $388 \pm 120$ \\
TC & $254 \pm 92$ & $21 \pm 13$ & $233 \pm 82$ & $6 \pm 4$ & $513 \pm 57$ \\
TD & $456 \pm 380$ & $10 \pm 3$ & $351 \pm 299$ & $4 \pm 3$ & $822 \pm 326$ \\
WA & $161 \pm 103$ & $24 \pm 10$ & $123 \pm 2$ & $11 \pm 12$ & $320 \pm 98$ \\
WB & $152 \pm 41$ & $33 \pm 10$ & $216 \pm 49$ & $8 \pm 9$ & $410 \pm 98$ \\
WC & $182 \pm 20$ & $28 \pm 19$ & $517 \pm 441$ & $11 \pm 7$ & $738 \pm 465$ \\
WD & $269 \pm 216$ & $11 \pm 4$ & $245 \pm 26$ & $7 \pm 7$ & $532 \pm 218$ \\
CA & $176 \pm 75$ & $12 \pm 2$ & $95 \pm 31$ & $4 \pm 8$ & $288 \pm 60$ \\
CB & $159 \pm 150$ & $16 \pm 4$ & $290 \pm 254$ & $4 \pm 2$ & $469 \pm 399$ \\
CC & $415 \pm 293$ & $52 \pm 64$ & $369 \pm 162$ & $9 \pm 5$ & $846 \pm 520$ \\
CD & $145 \pm 74$ & $14 \pm 13$ & $102 \pm 15$ & $15 \pm 8$ & $275 \pm 87$ \\
Species & & & & & \\
TA & $21 \pm 12$ & $8 \pm 3$ & $26 \pm 11$ & $1 \pm 2$ & $56 \pm 27$ \\
TB & $31 \pm 8$ & $7 \pm 3$ & $36 \pm 16$ & $1 \pm 1$ & $75 \pm 22$ \\
TC & $37 \pm 4$ & $7 \pm 2$ & $56 \pm 12$ & $2 \pm 1$ & $103 \pm 6$ \\
TD & $17 \pm 4$ & $4 \pm 2$ & $59 \pm 15$ & $3 \pm 1$ & $82 \pm 15$ \\
WA & $24 \pm 11$ & $7 \pm 2$ & $35 \pm 11$ & $2 \pm 2$ & $68 \pm 21$ \\
WB & $30 \pm 6$ & $8 \pm 3$ & $60 \pm 8$ & $3 \pm 1$ & $101 \pm 14$ \\
WC & $36 \pm 7$ & $8 \pm 2$ & $63 \pm 11$ & $4 \pm 1$ & $111 \pm 14$ \\
WD & $38 \pm 27$ & $6 \pm 2$ & $65 \pm 15$ & $3 \pm 1$ & $112 \pm 42$ \\
CA & $22 \pm 6$ & $7 \pm 2$ & $30 \pm 14$ & $1 \pm 1$ & $59 \pm 22$ \\
CB & $31 \pm 21$ & $9 \pm 1$ & $68 \pm 45$ & $2 \pm 2$ & $110 \pm 68$ \\
CC & $45 \pm 6$ & $8 \pm 2$ & $90 \pm 14$ & $4 \pm 2$ & $147 \pm 20$ \\
CD & $32 \pm 6$ & $4 \pm 3$ & $47 \pm 7$ & $3 \pm 1$ & $85 \pm 13$ \\
& & & & & \\
\hline
\end{tabular}

more of the total individuals on at least one sampling cruise. There was also little consistency in the identity of those species which were most abundant; only 7 species provided $1 \%$ or more of the individuals at a station 10 or more times out of a possible 21 occurrences. The most abundant species was an un-named syllid polychaete $(3.8 \%$ of individuals collected), and Prionospio nirripa was second in abundance $3.6 \%$ of individuals collected). At individual stations the percentage dominance by the most abundant species ranged from 5.8 to 26.8 but was generally less than 15 .

There were large seasonal differences in species composition at the stations. For example, 76 of the species found at Stn C2 in February were not found there in June, and 35 of the species found in June were not found in February; and 9 grabs taken at Stn W10 in September provided only 210 species while 9 grabs taken between September and the following June gave 432 species (see Fig. 6).

\section{Species-area curves}

Curves relating number of species to area sampled in September (Fig. 5) show that species richness was greatest in the Waygara area (Site W), with 453 species taken from 1.2 $\mathrm{m}^{2}$, and least in the Tyers area (Site T), with 371 species taken from 1.4 $\mathrm{m}^{2}$. Although the rate at which new species were collected decreased as the number of samples increased, the curves for each area were still rising sharply after all the samples had been included. On average the last 2 to 3 grabs in each area each added about 10 to 20 new species to the total species pool; but natural variation (as indicated by the standard deviations) is such that the last 2 or 3 samples could each have added 40 to 50 new species. The total number of species collected over the 3 areas, 619, is much higher than the values from the individual areas, which suggests there are considerable differences between the areas in species composition. This is confirmed by the curve for the 3 areas combined (Fig. 5d), which was still rising steeply after all 38 stations had been included.

The 9 grabs taken at Stn $\mathrm{W} 10$ in September (Fig. 6a) gave 210 species, about half the number of species taken in 9 grabs scattered throughout 

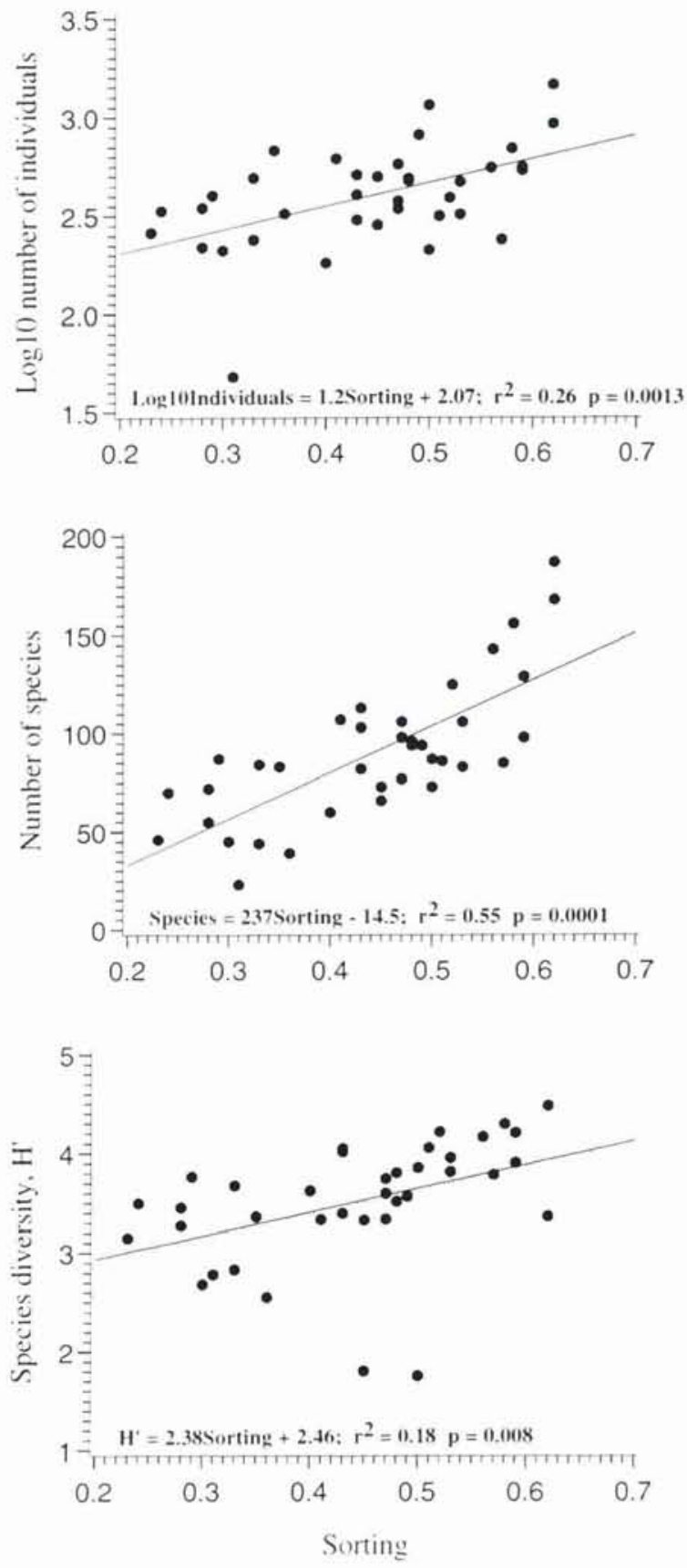

Fig. 3. Relationships between sediment sorting (sand fraction) and number of individuals, number of species, and species diversity

the Waygara area. Only 26 of the species at W10 were not taken at the other Waygara stations. In contrast, 9 seasonal grabs taken at Stn W10 (i.e. the first 3 replicates in September plus 3 replicates each in February and June) provided 432 species (Fig. 6b), almost 200 of which were not found at Waygara in September. Similarly, the seasonal samples taken at the Tyers stations included almost 200 species not taken in the area in
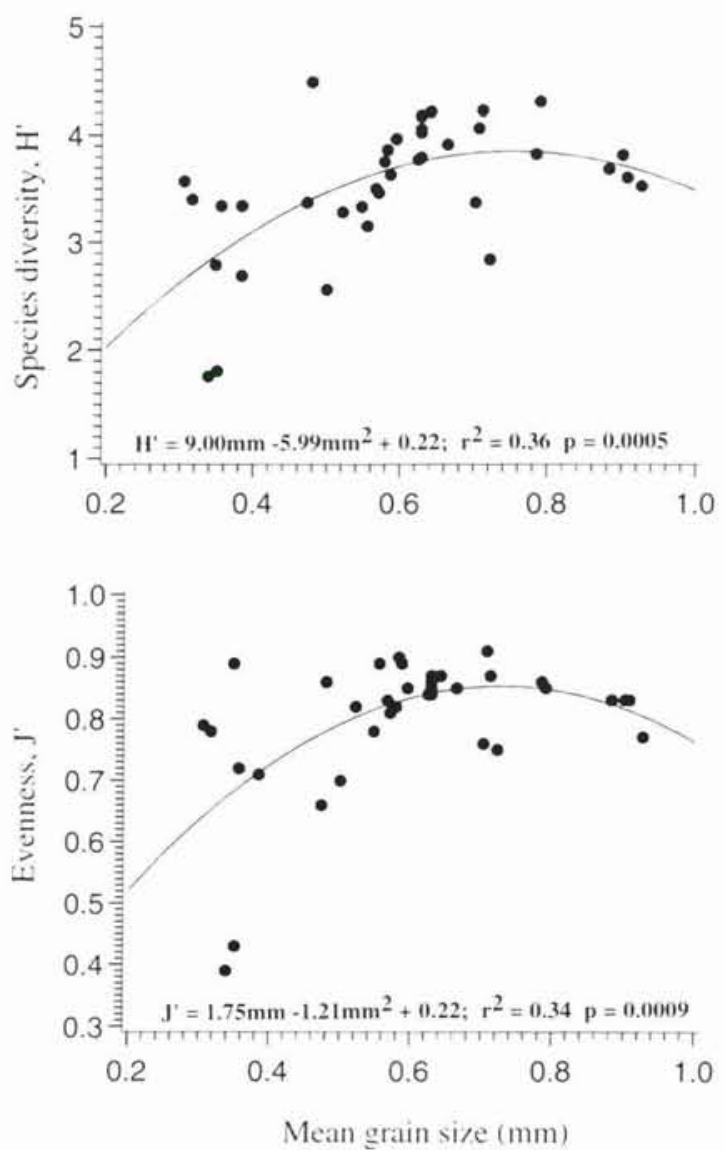

Fig. 4. Relationships between sediment mean grain size (sand fraction) and species diversity and evenness

September, and the seasonal samples at Cape Conran added almost another 100 species to those taken in September.

A curve of total species against total individuals collected over all areas and times (Fig. 7a) shows some levelling off at around 11000 to 13000 individuals, which represents the addition of the 9 replicate grabs taken from Stn W10 in September, begins to rise again when individuals from the remaining stations at Waygara are added, and begins to level out again at around 40000 to 44000 individuals, when all the individuals collected in September and about half of the individuals collected in the seasonal samples have been included. To estimate the number of species in the areas therefore requires sampling in both space and time.

A plot of total species per randomly selected 1000 s of individuals (Fig. 7 b) shows little variation in numbers of species for a given number of individuals. Maximum variation occurs at 1000 individuals with a standard deviation (7.4) of $3 \%$ of the mean (250) number of species. 
Table 3. Effects of partial correlation on relationships between fauna, depth and sediment characteristics (sand fraction). First value $(\mathrm{r}$ ) is the Pearson correlation coefficient and second value $(p)$ is probability

\begin{tabular}{|c|c|c|c|c|}
\hline \multirow{2}{*}{ Correlation } & & \multicolumn{3}{|c|}{ Partial correlation controlling for: } \\
\hline & & Sorting & Depth & Mean grain size \\
\hline No. of individuals and depth & $\mathrm{r}=0.54$ & 0.25 & & \\
\hline & $p=0.0006$ & & & \\
\hline No. of individuals and sorting & $\begin{array}{l}r=0.51 \\
p=0.0012\end{array}$ & & $\begin{array}{l}0.16 \\
0.34\end{array}$ & \\
\hline No. of species and depth & $\begin{array}{l}r=0.70 \\
p=0.0001\end{array}$ & $\begin{array}{l}0.27 \\
0.11\end{array}$ & & \\
\hline No. of species and sorting & $\begin{array}{l}r=0.74 \\
p=0.0001\end{array}$ & & $\begin{array}{l}0.42 \\
0.009\end{array}$ & \\
\hline$H^{\prime}$ and mean grain size & $\begin{array}{l}\mathrm{r}=0.50 \\
\mathrm{p}=0.002\end{array}$ & $\begin{array}{l}0.50 \\
0.002\end{array}$ & & \\
\hline$H^{\prime}$ and sorting & $\begin{array}{l}r=0.43 \\
p=0.008\end{array}$ & & & $\begin{array}{l}0.42 \\
0.009\end{array}$ \\
\hline
\end{tabular}

\section{DISCUSSION}

Grassle \& Maciolek (1992) suggested that, outside of the tropics, species richness was much higher in the deep sea than in shallow-water communities. Gray (1994) questioned this assumption and provided data from the Norwegian continental shelf showing species richness equal to, if not greater than, that shown in the deep-sea samples of Grassle \& Maciolek. The samples taken in East Gippsland add further support to the suggestion that species richness may not be exceptionally high in the deep sea. In passing Gray refers to the present survey ('...800 species have been found from $10 \mathrm{~m}^{2}$ in Bass Strait...') but remarks that quantitative data, which could be related to the deep-sea data of Grassle \& Maciolek, are absent. The quantitative data are presented here and the comparison can now be made, as can comparison with Gray's own data.

More species were collected in the present study than from the deep sea (Grassle \& Maciolek 1992) or from the Norwegian shelf (Gray 1994), but the studies are best compared by using cumulative species-individuals curves to determine numbers of species for a given number of individuals. The samples collected in East Gippsland in September gave 619 species from 18509 individuals. For a similar number of individuals samples from the Norwegian Shelf and the deep sea each gave about 400 species. Samples from the Norwegian shelf provided 620 species from 39582 individuals. For a similar number of individuals the East Gippsland samples provided 745 species and the deep-sea samples about 550 species. In total the East Gippsland samples provided 803 species from 60258 individuals. For a similar number of individuals the deep-sea samples provided about 600 species.

Considered simply as total number of species col- lected or as numbers of species per number of individuals, the East Gippsland fauna is richer than those reported from the deep sea and from the Norwegian shelf. In addition, the species richness of East Gippsland is further emphasised by the fact that samples were taken over a smaller and less ecologically diverse area than occurred in the other studies. The depth range sampled in East Gippsland (11 to $50 \mathrm{~m}$ ) was less than in the other studies $(70$ to $305 \mathrm{~m}$ for the Norwegian shelf, 1500 to $2500 \mathrm{~m}$ for the deep sea); the total area sampled (10.4 $\mathrm{m}^{2}$ ) was less than in the other studies $\left(50 \mathrm{~m}^{2}\right.$ for the Norwegian shelf, $21 \mathrm{~m}^{2}$ for the deep sea); the distance over which samples were taken $(50 \mathrm{~km}$ of the coast) was much less $(1200 \mathrm{~km}$ for the Norwegian shelf, $176 \mathrm{~km}$ for the deep sea); and the range of latitude over which samples were taken $\left(<0.1^{\circ}\right)$ was much less $\left(9^{\circ}\right.$ for the Norwegian samples, $1.2^{\circ}$ for the deep-sea samples).

Comparisons between the studies may also be influenced by the size of mesh through which samples were sieved. Grassle \& Maciolek (1992) used a $0.3 \mathrm{~mm}$ mesh

Table 4. Numbers of individuals $(n)$, species $(s)$, species diversity $\left(H^{\prime}\right)$ and evenness $\left(J^{\prime}\right)$ at seasonally sampled stations (September 1990 and February and June 1991). Values are for species and individuals summed over the 3 replicates at each station

\begin{tabular}{|lrrrrrr|}
\hline Stn & Depth (m) & Month & \multicolumn{1}{c}{$n$} & \multicolumn{1}{c|}{$s$} & $H^{\prime}$ & $J^{\prime}$ \\
\hline T3 & 11 & Sep & 1110 & 101 & 3.2 & 0.69 \\
W10 & 29 & Sep & 1355 & 150 & 4.2 & 0.84 \\
C18 & 50 & Sep & 930 & 149 & 4.1 & 0.82 \\
T3 & 11 & Feb & 1639 & 109 & 3.7 & 0.79 \\
T9 & 37 & Feb & 2669 & 259 & 4.5 & 0.81 \\
T18 & 43 & Feb & 2953 & 263 & 4.6 & 0.83 \\
W5 & 17 & Feb & 1006 & 91 & 3.6 & 0.80 \\
W10 & 29 & Feb & 6256 & 286 & 4.3 & 0.76 \\
W20 & 45 & Feb & 2990 & 286 & 4.7 & 0.83 \\
C2 & 23 & Feb & 1545 & 135 & 3.7 & 0.75 \\
C6 & 26 & Feb & 1294 & 150 & 4.0 & 0.80 \\
C18 & 50 & Feb & 1059 & 157 & 4.3 & 0.85 \\
T3 & 11 & Jun & 1278 & 111 & 3.5 & 0.74 \\
T9 & 37 & Jun & 2168 & 232 & 4.4 & 0.81 \\
T18 & 43 & Jun & 2392 & 228 & 4.3 & 0.79 \\
W5 & 17 & Jun & 992 & 85 & 3.1 & 0.70 \\
W10 & 29 & Jun & 2397 & 219 & 4.3 & 0.80 \\
W20 & 45 & Jun & 2518 & 288 & 4.7 & 0.83 \\
C2 & 23 & Jun & 913 & 83 & 3.4 & 0.77 \\
C6 & 26 & Jun & 1086 & 115 & 3.6 & 0.76 \\
C18 & 50 & Jun & 1827 & 171 & 3.7 & 0.72 \\
\hline
\end{tabular}




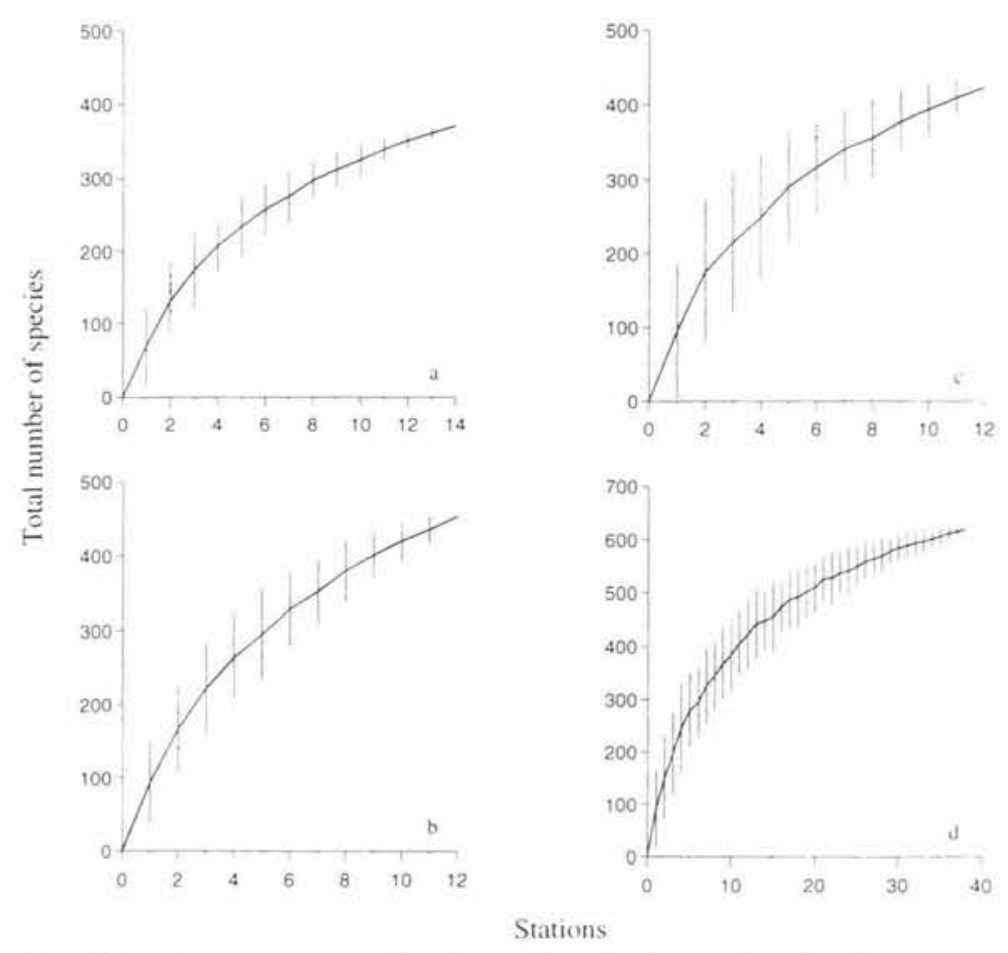

Fig. 5. Species-area curves for September 1990 samples showing mean numbers of species accumulated in random selections of 1 to 14 stations (each station $=0.1 \mathrm{~m}^{2}$ ). Vertical bars show $\pm 1 \mathrm{SD}$. (a) Tyers stations, total area sampled $=1.4 \mathrm{~m}^{2}$ and total species $=371$; (b) Waygara stations, total area sampled $=1.2 \mathrm{~m}^{2}$ and total species $=453 ;$; (c) Cape Conran stations, total area sampled $=1.2 \mathrm{~m}^{2}$ and total species $=422:$ (d) all samples, total area sampled $=3.8 \mathrm{~m}^{2}$ and total species $=619$

sieve, Gray (1994) used a $1 \mathrm{~mm}$ mesh sieve and in the present study a $0.5 \mathrm{~mm}$ mesh sieve was used. Because smaller mesh sizes retain a greater proportion of the individuals and species present (Bachelet 1990), the retention of species and individuals was likely to be greatest in the study by Grassle \& Maciolek, least in the study by Gray and intermediate in the present study. Gray (1994) argued that because the deep-sea fauna has a smaller average size than the continental shelf fauna, similar proportions of individuals and species will have been retained in the 2 studies despite the use of different mesh sizes. This argument may be justified; but the real point is that even though the retention of species was likely to have been greatest in the deep-sea study, the results in Grassle \& Maciolek (1992) do not convincingly show that species richness is greater in the deep sea than on the continental shelf of Norway or in the shallow water of East Gippsland. Perhaps one caveat that needs to be made, when comparing results obtained using different mesh sizes, is that moving from a larger to a smaller mesh may add a greater proportion of new individuals than of new species. If this is the case, species richness expressed as species per number of individuals would appear less in samples from the smaller than in those from the larger mesh.

Regression analysis gave clear indications that the fauna was influenced both by the depth of water from which samples were taken and by sediment type. The major influences were depth, mean grain size and sediment sorting. Correlations between sediment and fauna are complex and may in part reflect the influences of other factors, such as hydrodynamic and sediment transport processes, which affect the distribution of both sediment and fauna (Snelgrove \& Butman 1994). For example, well-sorted sediments occur in high-energy areas while poorly sorted sediments are associated with low-energy areas (Grebmeier et al. 1989). Snelgrove \& Butman (1994) commented that, while many studies have correlated invertebrate distribution with grain size, animal-sediment relationships are more variable than traditionally supposed and that no clear mechanism by which grain size per se limits distribution has been demonstrated. However, an explanation for the relationship between sorting (or other measures of grain-size diversity) and species richness has been suggested. Well-sorted sediments, because they offer a smaller range of grain sizes and of interstitial spaces, may provide fewer niches than poorly sorted sediments and so contain a less diverse fauna (Nichols 1970, Gray 1974, Etter \& Grassle 1992).

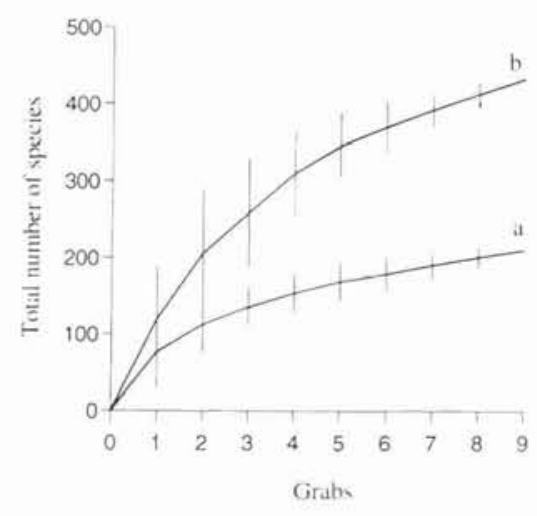

Fig. 6. Species-area curves showing mean numbers of species accumulated in random selections of 1 to 9 grabs (each grab $=$ $0.1 \mathrm{~m}^{2}$ ). Vertical bars show $\pm 1 \mathrm{SD}$. (a) grabs taken at Stn W10 in September 1990, total area sampled $=0.9 \mathrm{~m}^{2}$ and total species $=210$; (b) grabs collected seasonally at Stn W10 between September 1990 and June 1991, total area sampled $=0.9 \mathrm{~m}^{2}$ and total species $=432$ 

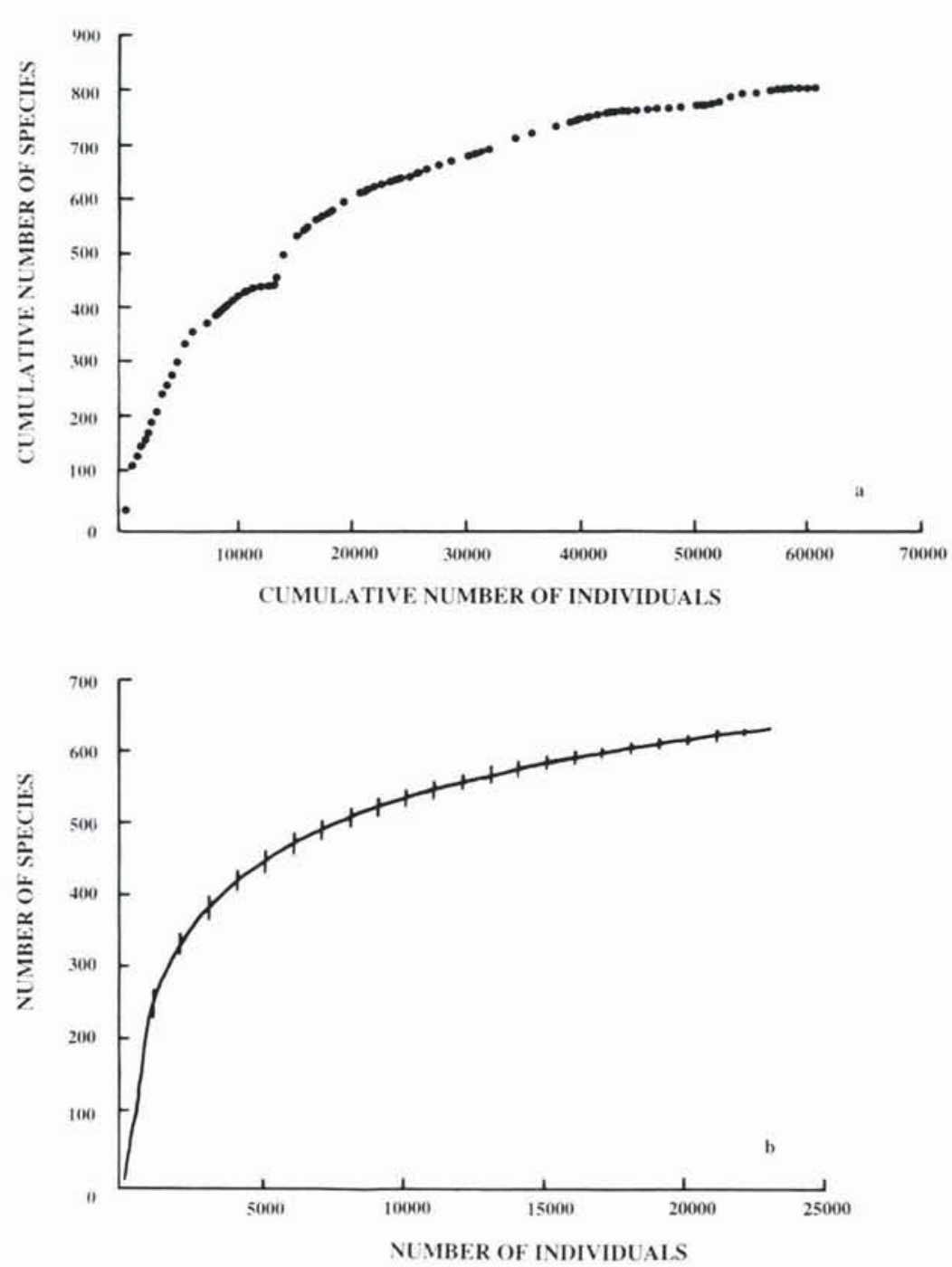

Fig. 7. (a) Plot of cumulative number of species against cumulative number of individuals for all samples added together in an ordered sequence (details in text). (b) Curves showing mean numbers of species accumulated in random selections of 1000 to 23000 individuals taken from the September samples. Vertical bars show $\pm 1 \mathrm{SD}$

Bass Strait is a high-energy environment. Mobile bottom sediments are found in water of less than $45 \mathrm{~m}$ depth, although wave action may affect bottom sediments in depths to $50 \mathrm{~m}$. The nature of the environment is reflected in the sediments, which typically are well-sorted medium to coarse sands with virtually no mud. Sediment sorting increases at shallower depths, indicating the increasing influence of wave action and an increasing homogeneity of the sedimentary environment. Species richness decreases as sorting increases, which is in agreement with the hypothesis that well-sorted sediments provide a relatively narrow range of niches for species to exploit. Because the wellsorted sediments are in shallower water, reduced species richness could also be due to increased physi- cal disturbance (through increased wave action) in these areas. Partial correlation suggests that sorting rather than depth is the major factor controlling species richness. The correlation with sorting still remains significant when the effects of depth are removed, but not vice-versa. For some other correlations (e.g. those between number of individuals, sorting and depth), it was not possible to assess the relative importances of depth and sorting since removing the effects of either rendered correlation with the other non-significant. In these instances it is perhaps some unmeasured factor related both to depth and sediment type which is influencing species distribution.

Relationships between species distributions and sediment type have been demonstrated for the deep sea, as they have for many other environments (Etter \& Grassle 1992, Snelgrove \& Butman 1994). Gray (1994) found no correlation between the fauna and depth or sediment type. He suggested that because physical disturbance is frequent on the continental shelf, organisms are likely to have 'broaderscale relationships to environmental factors' than is the case with deep-sea benthos. This suggestion is not supported by the present study. There were obvious relationships between species, sediment and depth even though samples were taken from physically disturbed habitats in shallow water and were from a more restricted range of sediment types than were the samples from the Norwegian shelf.

While the East Gippsland samples have revealed a community that is the most species-rich community so far investigated in Victoria, there is evidence that a relatively high level of species richness is typical of shallow-water communities in the state. The most studied faunas are those of Port Phillip Bay and Western Port. These are the 2 largest bays in Victoria and the sites of major industrial, commercial and urban development. Benthic surveys have listed 713 and 572 species from Port Phillip Bay and Western Port respectively (Poore et al. 1975, Coleman et al. 1978). These are high values compared with those from surveys in other temperate bays and estuaries throughout the northern and southern hemispheres (Boesch 1973, Maurer et al 1978, Jones \& Candy 1981, Lopez-Jamar 1981, Rainer 1982, Steimle 1982, Dauer et al. 1984, Jones et al. 1986, Carrasco et al. 1988, Steimle \& Carraciolo-Ward 1989), 
although differences in habitat type, sampling effort and methodology make exact comparisons between surveys difficult.

The relatively high species richness of Victoria's shallow waters has not previously gone unnoticed. In their study of the phoxocephalid amphipods of Australia, Barnard \& Drummond (1978) described Port Phillip Bay and Western Port as 'species packed' by comparison with similar embayments in other parts of the world. They could find no particular environmental features which might account for the high degree of species richness shown by the crustacean fauna. Similarly, the shallow-water community of East Gippsland may be considered as 'species-packed'. It is possible that species richness is high across all of southern Australia, an area with a largely endemic invertebrate and fish fauna (Poore 1994). Some data are available from shallow-water ( 15 to $20 \mathrm{~m}$ depth) samples taken off the open coast about $80 \mathrm{~km}$ to the west of the East Gippsland sites (Coleman unpubl. data). These samples have not been analysed in detail but do contain about 150 species not found in the East Gippsland samples, indicating that further sampling along the coast should add considerably to the species richness revealed by the present study.

Acknowledgements. Thanks are due to the boat crew and technical staff at the Marine and Freshwater Resources Institute for their work in the field. Dr Robin S. Wilson assisted with identification of polychaetes and in the maintenance of computer databases at the Museum of Victoria. Helen M. Lew Ton (Museum of Victoria) undertook most of the sorting and identification of samples and Sue Boyd (Museum of Victoria) provided help with mollusc identifications.

\section{LITERATURE CITED}

Bachelet G (1990) The choice of a sieving mesh size in the quantitative assessment of marine macrobenthos: a necessary compromise between aims and constraints. Mar Environ Res 30:21-35

Barnard JL, Drummond M (1978) Gammaridean Amphipoda of Australia, Part III: the Phoxocephalidae. Smithsonian Contributions to Zoology No. 245. Smithsonian Institution Press, Washington, DC

Boesch DF (1973) Classification and community structure of macrobenthos in the Hampton Roads area, Virginia. Mar Biol 21:226-244

Carrasco FD, Gallard VL, Medrano S (1988) Sublittoral macrobenthic infaunal assemblages of two nearby embayments from central Chile. Int Rev Gesamten Hydrobiol 73:441-455

Coleman N (1996) A survey of benthic and fish communities off the coast of East Gippsland, Victoria. Tech Rep. Marine and Freshwater Resources Institute, Queenscliff, Victoria, Australia

Coleman N, Cuff W, Drummond M, Kudenov JD (1978) A quantitative survey of the macrobenthos of Western Port, Victoria. Aust J Mar Freshwat Res 29:445-466
Dauer DM, Stokes TL Jr, Barker HR Jr, Ewing MR, Sourbeer JW (1984) Macrobenthic communities of the lower Chesapeake Bay. IV. Bay-wide transects and the inner continental shelf. Int Rev Gesamten Hydrobiol 69:1-22

Etter RJ, Grassle JF (1992) Patterns of species diversity in the deep-sea as a function of sediment particle size diversity. Nature 360:576-578

George AD, Black KP (1991) Settling tube analysis of sediment samples from eastern Bass Strait. Victorian Institute of Marine Sciences. Melbourne, Australia

Grassle JF, Maciolek NJ (1992) Deep-sea species richness: regional and local diversity estimates from quantitative bottom samples. Am Nat 139:313-340

Gray JS (1974) Animal-sediment relationships, Oceanogr Mar Biol Annu Rev 12:223-261

Gray JS (1994) Is deep-sea species diversity really so high? Species diversity of the Norwegian Continental shelf. Mar Ecol Prog Ser 112:205-209

Grebmeier JM, Feder HM, McRor CP (1989) Pelagic-benthic coupling on the shelf of the northern Bering and Chukchi seas. II. Benthic community structure. Mar Ecol Prog Ser 51:253-268

Hessler RR, Sanders HL (1967) Faunal diversity in the deep sea. Deep Sea Res 14:65-78

Jones AR, Watson-Russell CJ, Murray A (1986) Spatial patterns in the macrobenthic communities of the Hawkesbury estuary, New South Wales. Aust J Mar Freshwat Res $37: 521-543$

Jones G, Candy S (1981) Effect of dredging on the macrobenthic infauna of Botany Bay. Aust J Mar Freshwat Res 32: 379-398

Lopez-Jamar E (1981) Spatial distribution of the infaunal benthic communities of the Ria de Muros, North-West Spain. Mar Biol 63:29-37

Maurer D. Watling L, Leathem W. Wethe C (1978) Benthic invertebrate assemblages of Delaware Bay. Mar Biol 45: $65-78$

Nichols FH (1970) Benthic polychaete assemblages and their relationship to the sediment in Port Madison, Washington. Mar Biol 6:48-57

Parry GD, Campbell SJ, Hobday DK (1990) Marine resources off East Gippsland, southeastern Australia. Mar Sci Lab Tech Rep No. 72, Queenscliff, Victoria, Australia

Poore GCB (1994) Marine biogeography of Australia. In: Hammond LS, Synnot RN (eds) Marine biology. Longman Cheshire, Melbourne, p 189-212

Poore GCB, Rainer SF, Spies RB, Ward E (1975) The zoobenthos program in Port Phillip Bay, 1969-73. Fisheries and Wildlife Paper, Victoria, No. 7. Division of Fisheries and Wildlife, Victoria

Poore GCB, Wilson GDF (1993) Marine species richness. Nature 361:597-598

Rainer SF (1982) Trophic structure and production in the macrobenthos of a temperate Australian estuary. Estuar Coast Shelf Sci 15:423-441

Sanders HL (1968) Marine benthic diversity: a comparative study. Am Nat 102:243-282

Snelgrove PRV, Butman CA (1994) Animal-sediment relationships revisited: cause versus effect. Oceanogr Mar Biol Annu Rev 32:111-177

Steimle FW Jr (1982) The benthic macroinvertebrates of the Block Island Sound. Estuar Coast Shelf Sci 15:1-16

Steimle FW, Caracciolo-Ward J (1989) A reassessment of the status of the benthic macrofauna of the Raritan Estuary. Estuaries 12:145-156

Manuscript received: May 28, 1996

Revised version accepted: May 13, 1997 